\title{
EDitorial
}

\section{Um novo ciclo de cem anos da Revista de Medicina se inicia}

\author{
A new centenary of Revista de Medicina begins
}

\section{Viktor Sinkunas}

Após o ano do centenário de trajetória da Revista de Medicina em 2016², no qual participei como colaborador, tive a honra de continuar o processo editorial da Rev Med como Editor Chefe em 2017. Um momento da Revista em que era necessário aumentar a eficiência da revisão por pares, montar novas parcerias, ampliar a presença do periódico em mais faculdades do país e impulsionar mais acadêmicos para a escrita científica. Essas demandas foram as que mobilizaram a diretoria deste ano da Rev Med para que pudéssemos iniciar um novo ciclo de cem anos do periódico igualmente brilhante como o primeiro. E que honrássemos o nobre trabalho das centenas de acadêmicos, docentes e profissionais da área médica que passaram pela Revista de Medicina, e que depositaram seus esforços para o engrandecimento deste periódico².

A equipe editorial se empenhou em convocar mais avaliadores qualificados e conseguimos passar dos 77 revisores do ano anterior para os 258 atuais. O que contribuiu com a publicação dentro dos prazos das quatro edições de 2017 com um total de 53 artigos, sendo 25 artigos originais, 10 de revisão, 9 relatos de caso e 9 contribuições como cartas ao editor e editoriais (Figura 1).

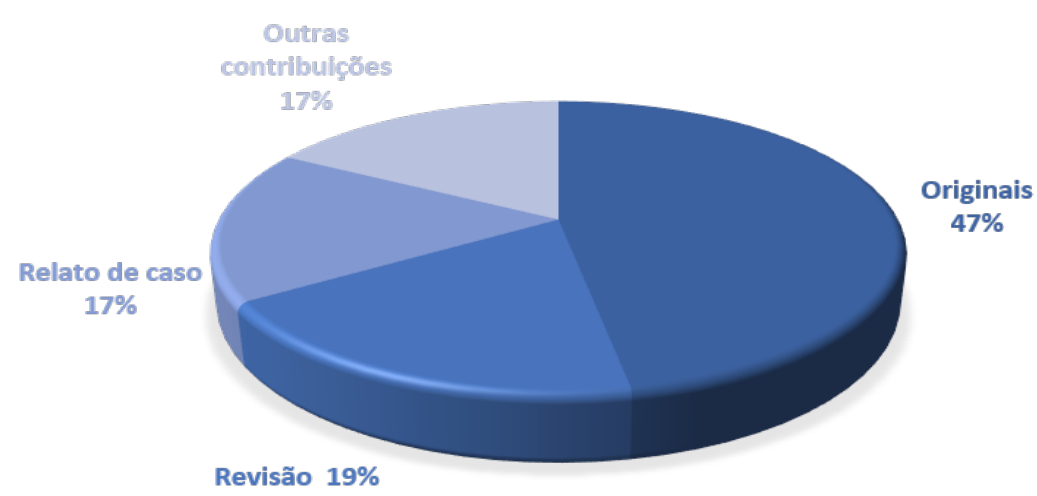

Figura 1: Percentual de artigos publicados por tipos de artigos em 2017

Acadêmico do $3^{\circ}$ ano da Faculdade de Medicina da Universidade de São Paulo FMUSP. Editor Chefe da Revista de Medicina. Coordenador do Departamento Científico da FMUSP. Email: viktor.sinkunas@fm.usp.br. 
Ao estudarmos a história da Revista de Medicina³ $^{3}$ vemos que desde sua formação em 1916, a importância de disseminar os princípios que devem guiar a profissão médica foi parte das tarefas do periódico. Essa divulgação de boas práticas e de inovação aumentou esse ano com a manutenção das parcerias da Rev Med com os maiores congressos médicos acadêmicos (COMU e Braincoms), com a primeira apresentação da Revista no Congresso da Associação Brasileira das Ligas Acadêmicas de Cirurgia (São Paulo) e com a participação ativa na organização científica do I Congresso Acadêmico de Medicina do Espírito Santo. O contato e conversa com acadêmicos das diversas faculdades de medicina do Brasil possibilitou uma diversificação nas instituições de origem dos autores e artigos publicados nesse ano. Contabilizando artigos originais, de revisão e relatos de caso, a Revista de Medicina, em 2017, teve 58\% das publicações de fora do estado de São Paulo, o que comprova a ampliação nacional do periódico (Figura 2).

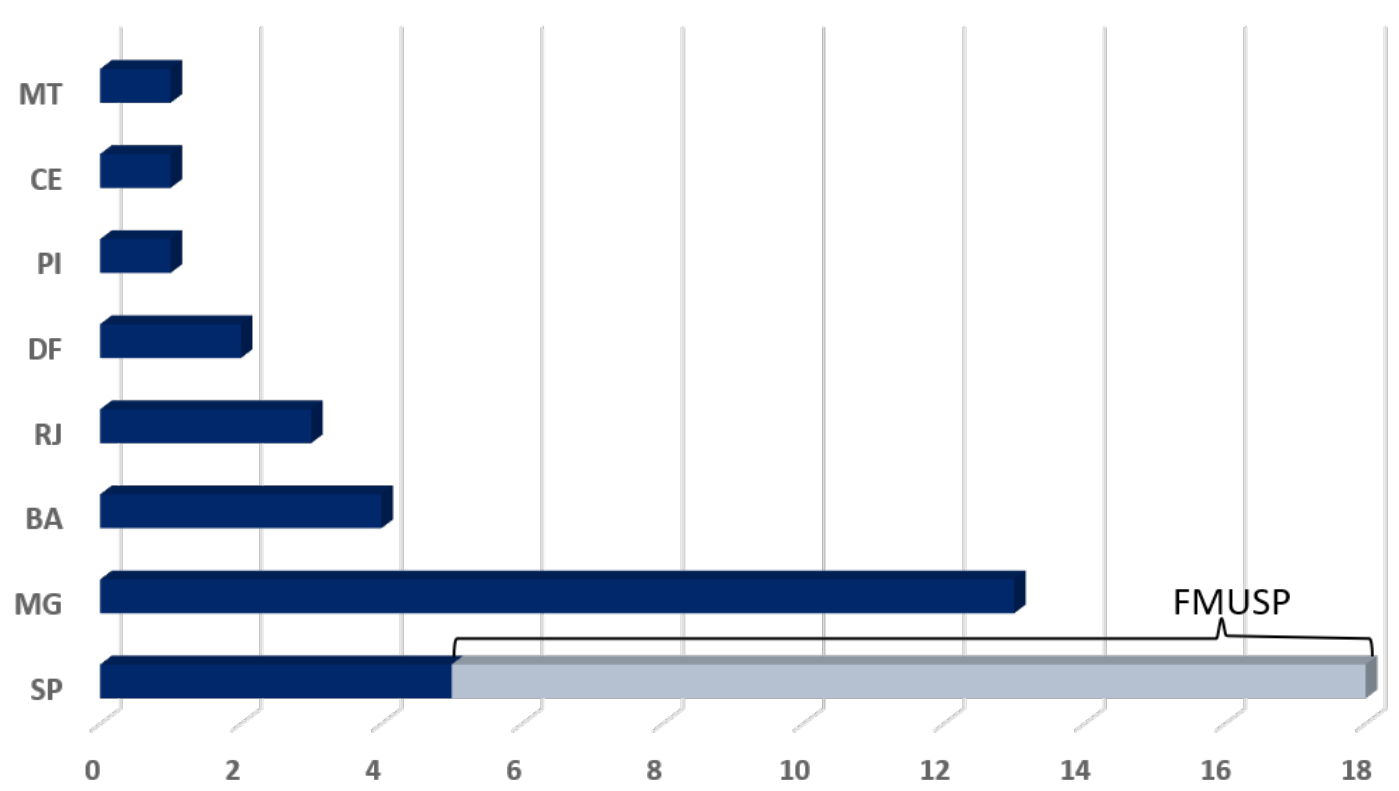

Figura 2: Número de artigos publicados pela Revista de Medicina por estados em 2017

Com o objetivo de disseminar a cultura da publicação científica na graduação médica do país, o projeto de Núcleos Editoriais Associados (NEAs), elaborado pela diretoria de 2015 da Revista, foi revigorado com a implementação de dois núcleos esse ano, um deles na Universidade Federal do Paraná e o outro no Estado do Espírito Santo com a participação das cinco faculdades de medicina do estado. O eixo principal da abertura desses núcleos, coordenados por um editor associado acadêmico, é relacionado à implementação da "Abordagem Prática à Escrita Científica”. Esse projeto já se solidificou, nos últimos três anos, na Faculdade de Medicina da Universidade de São Paulo - FMUSP onde de 6 a 7 grupos de acadêmicos e docentes desenvolvem artigos de revisão sistemática em inglês para avaliação e publicação pela Revista sob supervisão do responsável pela Coordenação da Disciplina de Optativa da Revista. Esse modelo de ensino de escrita científica agora está sendo montado nos NEAs com a participação como orientadores de grandes nomes da área da saúde nacionais, e com potencial de se expandir por diversos cursos médicos.

Após reunião com a SciELO durante o ano e conversa com editores de revistas científicas nacionais de alto impacto, a gestão 2017 iniciou o projeto de internacionalização da Revista, que tem como objetivo novas indexações em bases de dados internacionais. Os dados oriundos do Portal de Revistas da USP, no qual estamos indexados, mostram que de janeiro a dezembro desse ano a Revista de Medicina obteve acesso em um total de 89 países o que sustenta a nossa ideia de que é possível transformar o periódico científico acadêmico 
mais antigo do mundo ainda em circulação em uma revista de projeção internacional. De todos os acessos em 2017, retirando os que não foram possíveis de se averiguar a nacionalidade, obtivemos $20 \%$ (mais de 11 mil) de acessos de fora do Brasil (Figura 3).

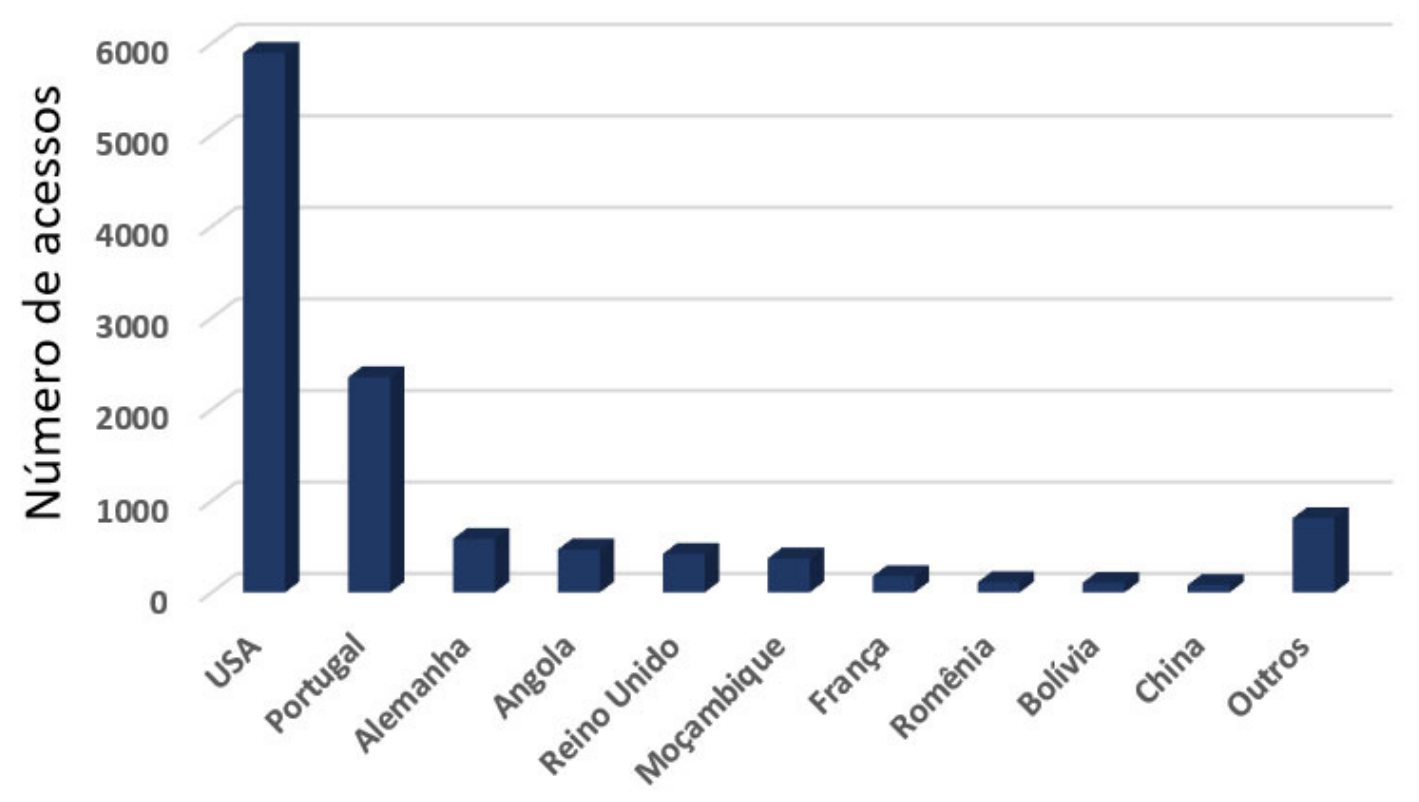

Figura 3: Os 10 países estrangeiros que mais acessaram a Revista em 2017

\section{Agradecimento}

Todo o trabalho desse ano como Editor Chefe não aconteceria ou seria gratificante sem a ajuda de várias pessoas que acreditaram nos projetos da Revista. Sou grato ao Editor Executivo, Guilherme Yuiti Sikusawa, que dividiu comigo a responsabilidade em liderar o periódico, aos outros membros da diretoria da Rev Med, Thamara R. da Costa, Victor E. K. Sakaguchi, Thiago M. S. Rios e Vitor C. Romano, que trabalharam com maestria em suas funções. À Secretária Executiva, Suely Campos Cardoso, que além de trabalhar com maestria tem o mesmo sentimento de carinho por esse periódico, minha gratidão.

Aos colaboradores que sempre se disponibilizaram em auxiliar na organização e resolução de demandas diárias da Revista, Bárbara, Diana, Giulia, Daniela e àqueles que continuarão a fazer parte em 2018, Bárbara N. Kumagai, Paula G. Coelho, Nathalia F. M. Tejada, Luiz G. Gonçalves e Camila Sarro, meu sincero agradecimento. Às gestões anteriores, em especial ao Robert Z. Pfann e Gustavo R. Gameiro, meu reconhecimento pelo trabalho árduo e também pela consultoria esse ano.

Além do corpo discente, foi uma grande honra poder ser respaldado e aconselhado por grandes mestres: Prof. Dr. Jose Otavio Costa Auler Jr., Prof. Dr. Flavio Fava de Moraes, Prof. Dr. Edmund C. Baracat, Profa. Dra. Magda M. S. Carneiro Sampaio, Prof. Dr. Luiz Felipe Pinho Moreira, Dr. Luciano F. Drager e Dra. Cristina Camargo.

Acredito que apresentamos excelentes resultados e que o ano 2018 será mais um em que o trabalho de todos que são a Revista de Medicina inovará, ainda mais, o conhecimento científico. 


\section{REFERÊNCIAS}

1. Cardoso SC, Sanchez FR, Freitas TQ, Polho GB, Gameiro GR. Revista de Medicina e sua trajetória: 1916 a 2016. In: XV ENEC Encontro de Editores Científicos, Florianópolis, SC, 22-24 nov. 2015. Disponível em: http://ocs.abecbrasil.org.br/index.php/ENEC/ enec/paper/viewFile/100/103.

2. Oliveira AB, Longo PW. 1924. A direcção da Revista. Rev Med (São Paulo). 1924;6(36):1-2. Disponível em: http://www.revistas. usp.br/revistadc/article/view/56975/59969.

3. Mota A. 2012. A Revista de Medicina: entre histórias e registros, 1916-1940. Rev Med (São Paulo). 2012;91:5-12. https://www. revistas.usp.br/revistadc/article/view/59052/62039. 